\title{
Aspirin Bioactivity for Prevention of Cardiovascular Injury in COVID-19
}

\author{
Temistocles Diaz ${ }^{1,2}$, Barry H. Trachtenberg ${ }^{3}$, Samuel J. K. Abraham ${ }^{4,5,6}$, \\ Rao KosagiSharaf ${ }^{2 *}$ and Armando A. Durant-Archibold ${ }^{2,7 *}$ \\ ${ }^{1}$ Internal Medicine-Interventional Cardiology, Department of Cardiology, Punta Pacifica Hospital, Affiliate of John Hopkins \\ Medicine International, Panama City, Panama, ${ }^{2}$ Biomedicine Research Unit, Center for Biodiversity and Drug Discovery, \\ Instituto de Investigaciones Científicas y Servicios de Alta Tecnología (INDICASAT Asociation of Public Interest), Panama City, \\ Panama, ${ }^{3}$ Department of Cardiology, Houston Methodist DeBakey Heart and Vascular Center, Houston, TX, United States, \\ ${ }^{4}$ Department of Surgery \& Centre for Advancing Clinical Research (CACR), Yamanashi University, Chuo, Japan, ${ }^{5}$ Edogawa \\ Evolutionary Laboratory of Science (EELS), Edogawa Hospital, Tokyo, Japan, ${ }^{6}$ The Mary-Yoshio Translational Hexagon \\ (MYTH), Nichi-In Centre for Regenerative Medicine (NCRM), Chennai, India, ${ }^{7}$ Department of Biochemistry, College of Natural, \\ Exact Science and Technology, Universidad de Panama, Panama City, Panama
}

Keywords: molecular mechanisms, aspirin, SARS-CoV-2, COVID-19, prevention of cardiovascular disease

\section{INTRODUCTION}

OPEN ACCESS

Edited by:

Shaista Malik,

University of California, Irvine,

United States

Reviewed by:

Hack-Lyoung Kim,

Seoul Metropolitan Government Seoul National University Boramae Medical Center, South Korea

*Correspondence:

Rao KosagiSharaf

jrao@indicasat.org.pa

Armando A. Durant-Archibold adurant@indicasat.org.pa

Specialty section:

This article was submitted to Cardiovascular Epidemiology and

Prevention,

a section of the journal

Frontiers in Cardiovascular Medicine

Received: 26 May 2020 Accepted: 10 November 2020 Published: 30 November 2020

Citation:

Diaz $T$, Trachtenberg $B H$, Abraham SJK, KosagiSharaf $R$ and Durant-Archibold AA (2020) Aspirin Bioactivity for Prevention of Cardiovascular Injury in COVID-19. Front. Cardiovasc. Med. 7:562708. doi: 10.3389/fcvm.2020.562708
The coronavirus disease 2019 (COVID-19), caused by the severe acute respiratory syndrome coronavirus 2 (SARS-CoV-2), has come to be one of the gravest pandemics of the last two centuries. WHO epidemiological records on COVID-19 outbreak confirmed more than 35 million cases and 1 million deaths worldwide since the disease have originated in Wuhan, China $(1,2)$. Although clinical treatment of COVID-19 patients focuses on the pulmonary complications and acute respiratory distress syndrome (ARDS), medical reports have also pointed toward the severe deterioration of the patient's state of health due to cardiovascular complications. Furthermore, cardiovascular comorbidities have been determined as key factors of mortality for SARS-CoV-2 infected patients, which present high blood levels of cardiac-specific proteins troponin I and/or $\mathrm{T}$, indicative signs of hypoxia, tachyarrhythmia, myocarditis, and myocardial injury (3-8). Other cardiovascular injuries associated with COVID-19 are venous and arterial thrombosis, and venous thromboembolism (VTE). Case studies performed on COVID-19 patients, and autopsies conducted on those who died due to cardiovascular complications such as stroke and acute coronary syndromes, point to thrombotic disease as a critical factor of mortality in severe cases of COVID-19 (9-12).

Severe cases of SARS-COV-2 infected patients experience lymphocytopenia and a high activation of metabolic proinflammatory cytokines mechanisms which leads to an elevated blood concentration of interleukin (IL) 2 (IL-2), IL-6, IL-7, interferon gamma (IFN- $\gamma$ ), macrophage inflammatory protein- 1 alpha (MIP1A), and tumor necrosis factor alpha (TNF- $\alpha$ ) pro-inflammatory cytokines $(4,13)$. This high level of cytokines, known as cytokine storm syndrome (CSS), tends to be a critical factor of morbidity and mortality for COVID-19 patients. CSS contributes to the upregulation of metabolic coagulation pathways resulting in damage to the endothelium, and therefore to the cardiovascular system (14-16). Furthermore, oxygen deprivation seems to mediate the hypercoagulability in COVID-19 (9). Patients with severe COVID-19 pneumonia progress to ARDS, accompanied by disseminated intravascular coagulation (DIC) (17), which may upregulate the coagulation pathways by activation of procoagulant factors, such as tissue factor, leading to both arterial and venous thrombotic disease. These biochemical mechanisms are main factors associated with disturbance of blood coagulation in COVID-19 patients. On the other hand, there is a potential risk of VTE associated with administration of some medications to severe cases of COVID-19 (18). Clinical reports have indicated thrombotic disease in around 25-30\% SARS-CoV-2 infected patients, mainly in seriously ill patients $(9,10,12,19-22)$. Therefore, early 
anticoagulant treatment certainly leads to a better prognosis. In this sense, the antithrombotic properties of aspirin make it a plausible drug for thrombotic disease prevention, the efficacy of which requires to be validated in COVID-19 patients.

Acetylsalicylic acid, aspirin, is an antiplatelet drug that inhibits platelet aggregation. The main biochemical mechanism by which aspirin inhibits thrombotic damage is through irreversible inactivation of cyclooxygenase 1 (COX-1) enzyme. In this respect, aspirin acetyl group attaches to the active side of COX-1 at S529, inhibiting the biosynthesis of prostaglandin H2 (PGH2), which is the substrate of thromboxane-A synthase that catalyzes the generation of the prothrombotic eicosanoid thromboxane A2 (TXA2) (Figure 1) suppressing platelet aggregation leading to the prevention of VTE without significant alterations in the endothelial function. On the other hand, aspirin acetylates fibrinogen and other proteins involved in blood coagulation, also preventing thrombus formation. These biochemical mechanisms cause a decrease of dense granule release from platelets (23, 24). Activated platelets and endothelial cells biosynthesize Pselectin, a cell-adhesion glycoprotein that promotes leukocyte and platelet adhesion, and the attachment of leukocytes to the vascular endothelium. Aspirin inhibits P-selectin, which results in the reduction of deep vein thrombosis (DVT) (25). Other antithrombotic mechanism of aspirin involves upregulation of nitric oxide (NO) metabolic production by endothelial cells, through inhibition prostacyclin synthesis, which leads to platelet inactivation (26). Additionally, aspirin prevents the formation of the serine protease enzyme thrombin, which catalyzes the transformation of fibrinogen to fibrin and, hence, leads to the formation of blood clot. Furthermore, thrombin is a potent mediator of platelet activation and aggregation. Thrombin promotes its biosynthesis by feedback activation of prothrombinase complex coenzymes (factors V and VIII). Aspirin inhibits tissue factor (TF): Factor VIIa (FVIIa) complex that catalyzes thrombin formation and, therefore, thrombinmediated coagulation pathways (24).

Aspirin is certainly one of the most used drugs in medicine. In addition to its antithrombotic activity, aspirin is very wellknown for its antipyretic, antiviral, and analgesic properties (27). Aspirin bioactivity inhibits virus replication such as influenza virus, hepatitis $\mathrm{C}$ virus, and flavivirus. Among the reported metabolic mechanisms that produces inhibition is the activation of mitogen-activated protein kinase/extracellular signal-regulated kinase kinase $1 / 2$ and p38 mitogen-activated protein kinase. Furthermore, an additional mechanism is the inhibition of the proinflammatory transcription factor NF-кB which is relevant for viral genes expression (28). Clinical studies have reported reduction in the rate of stroke, peripheral artery disease, thromboembolism, and myocardial infarction (MI). At present, aspirin is recommended for primary and secondary prevention of stroke, anterior MI with left ventricular thrombus, peripheral artery disease, and acute coronary syndrome (29, 30). A multicenter, double-blind, placebo-controlled study WARFASA (the Aspirin for the Prevention of Recurrent Venous Thromboembolism Warfarin and Aspirin) for the assessment of the efficacy of aspirin for prevention and treatment of VTE, which included 403 patients, showed a lower VTE in patients who received aspirin than in patients not receiving antithrombotic treatment (28 [6.6\%] of 205 patients vs. 43 [11.2\%] of 197 patients) (31). Furthermore, in a more recent

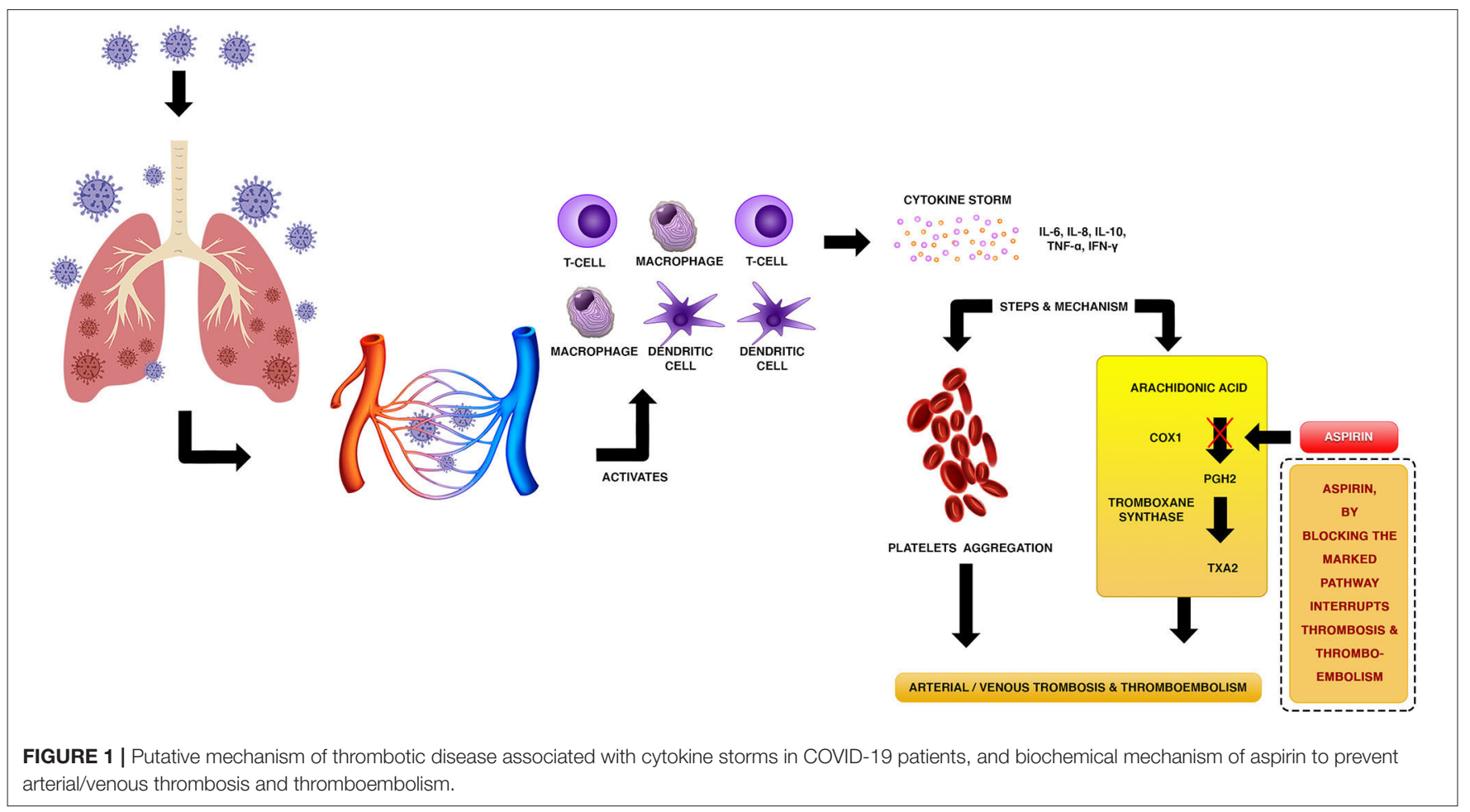


clinical trial of 1,224 patients on the prevention of recurrent unprovoked venous thromboembolism by aspirin, performed by the International Collaboration of Aspirin Trials for Recurrent Venous Thromboembolism (INSPIRE), it was found that aspirin reduces the risk of recurrence of DVT by $34 \%$, without significantly increasing the risk of bleeding (32). Clinical studies from China showed that ARDS developed in a short period of time in COVID-19 patients, which leads to a high number of deaths in severe cases of the disease $(74 \%)(33,34)$. ARDS causes uncontrolled coagulation disfunction in severely ill patients (35). Clinical trials reported a decrease in number of cases of ARDS in patients treated with aspirin, which is can be explained by the antithrombotic properties of the drug (36). On the other hand, there are an important number of clinical investigations, registered at ClinicalTrials.gov, which are currently studying the bioactivities of aspirin in COVID-19 patients (NCT04365309; NCT04363840; NCT04333407; NCT04343001; NCT04324463; NCT04368377; NCT04410328; NCT04425863; NCT04466670; NCT04498273) (37).

In the light of the evidence discussed in this article, it is clear that patients infected with SARS-CoV-2 virus experience an increment of proinflammatory cytokine molecules, which is a main factor that leads to abnormal platelet aggregation, which causes thrombosis and thromboembolism in COVID-19 patients. Thrombotic disease leads to alterations of many organs, mainly the lung, and the cardiovascular system. Treatment of patients in early stages of COVID-19 with low-dose aspirin (75-100 mg) represents an important pharmacological strategy for prevention of platelet aggregation, which leads to a predictable potential disease progression of arterial/venous

\section{REFERENCES}

1. World Health Organization. Coronavirus Disease 2019 (COVID-19). Available online at: www.who.int/emergencies/diseases/novel-coronavirus-2019 (accessed October 6, 2020).

2. Olum R, Chekwech G, Wekha G, Nassozi DR, Bongomin F. Coronavirus disease-2019: knowledge, attitude, and practices of health care workers at makerere university teaching hospitals, Uganda. Front Public Health. (2020) 8:181. doi: 10.3389/fpubh.2020.00181

3. Banerjee A, Pasea L, Harris S, Gonzalez-Izquierdo A, Torralbo A, Shallcross L, et al. Estimating excess 1-year mortality associated with the COVID-19 pandemic according to underlying conditions and age: a population-based cohort study. Lancet. (2020). doi: 10.1016/S0140-6736(20)30854-0

4. Wang L, Zhang Y, Zhang S. Cardiovascular impairment in COVID-19: learning from current options for cardiovascular anti-inflammatory therapy. Front Cardiovasc Med. (2020) 7:78. doi: 10.3389/fcvm.2020.00078

5. Li B, Yang J, Zhao F, Zhi L, Wang X, Liu L, et al. Prevalence and impact of cardiovascular metabolic diseases on COVID-19 in China. Clin Res Cardiol. (2020) 109:531-8. doi: 10.1007/s00392-020-01626-9

6. Kang Y, Chen T, Mui D, Ferrari V, Jagasia D, Scherrer-Crosbie M, et al. Cardiovascular manifestations and treatment considerations in COVID-19. Heart. (2020) 106:1132-41. doi: 10.1136/heartjnl-2020-317056

7. Guzik TJ, Mohiddin SA, Dimarco A, Patel V, Savvatis K, Marelli-Berg FM, et al. COVID-19 and the cardiovascular system: implications for risk assessment, diagnosis, and treatment options. Cardiovasc Res. (2020) 116:1666-87. doi: 10.1093/cvr/cvaa106

8. Guo T, Fan Y, Chen M, Wu X, Zhang $\mathrm{L}, \mathrm{He} \mathrm{T}$, et al. Cardiovascular implications of fatal outcomes of patients with thrombosis and thromboembolism, based on the metabolic mechanisms of action of this drug. The incorporation of aspirin therapeutical evaluation into clinical trials that studies the effectiveness of the drug on early stages patients with COVID19 , as well as its concomitant use with antiviral drugs, will enhance our knowledge regarding the physiological factors which promotes health and the development of more accurate therapeutical protocols.

\section{AUTHOR CONTRIBUTIONS}

$\mathrm{RK}$ and $\mathrm{AD}-\mathrm{A}$ started the debate topic. TD, BT, SA, RK, and $\mathrm{AD}-\mathrm{A}$ participated in discussions and made substantial contributions to the conception of the work, and writing of the manuscript. All authors read and agreed to its submission. All authors contributed to the article and approved the submitted version.

\section{FUNDING}

This work was supported by National System of Research Awards (SNI) of Panama; Institute of Scientific Research and High Technology Services.

\section{ACKNOWLEDGMENTS}

$\mathrm{RK}$ and $\mathrm{AD}-\mathrm{A}$ gratefully acknowledge the support received through the National System of Research Awards (SNI) of Panama. We acknowledge Rita Marissa Giovani for technical support. coronavirus disease 2019 (COVID-19). JAMA Cardiol. (2020) 5:811-18. doi: 10.1001/jamacardio.2020.1017

9. Klok FA, Kruip MJHA, van der Meer NJM, Arbous MS, Gommers DAMPJ, Kant KM, et al. Incidence of thrombotic complications in critically ill ICU patients with COVID-19. Thromb Res. (2020) 191:1457. doi: $10.1016 /$ j.thromres.2020.04.013

10. Ranucci M, Ballotta A, Di Dedda U, Bayshnikova E, Dei Poli M, Resta M, et al. The procoagulant pattern of patients with COVID-19 acute respiratory distress syndrome. J Thromb Haemost. (2020) 18:174751. doi: $10.1111 /$ jth. 14854

11. Bikdeli B, Madhavan MV, Jimenez D, Chuich T, Dreyfus I, Driggin E, et al. COVID-19 and Thrombotic or thromboembolic disease: implications for prevention, antithrombotic therapy, and follow-up. J Am Coll Cardiol. (2020) 75:2950-73. doi: 10.1016/j.jacc.2020.04.031

12. Wichmann D, Sperhake JP, Lütgehetmann M, Steurer S, Edler C, et al. Autopsy findings and venous thromboembolism in patients with COVID-19: a prospective cohort study. Ann Intern Med. (2020). doi: 10.7326/M20-2003

13. Coperchini F, Chiovato L, Croce L, Magri F, Rotondi M. The cytokine storm in COVID-19: an overview of the involvement of the chemokine/chemokine-receptor system. Cytokine Growth Factor Rev. (2020) 53:25-32. doi: 10.1016/j.cytogfr.2020.05.003

14. Levi $M$, van der Poll $\mathrm{T}$, Büller $\mathrm{H}$ R. Bidirectional relation between inflammation and coagulation. Circulation. (2004) 109:2698-704. doi: 10.1161/01.CIR.0000131660.51520.9A

15. Ozeren A, Aydin M, Tokac M, Demircan N, Unalacak M, Gurel A, et al. Levels of serum IL-1beta, IL-2, IL-8 and tumor necrosis factor-alpha in patients with unstable angina pectoris. Mediators Inflamm. (2003) 12:3615. doi: 10.1080/09629350310001633360 
16. Levi M, Poll T. Coagulation in patients with severe sepsis. Semin Thromb Hemost. (2015) 41:9-15. doi: 10.1055/s-0034-1398376

17. Whyte C, Morrow G, Mitchell J, Chowdary P, Mutch N. Fibrinolytic abnormalities in acute respiratory distress syndrome (ARDS) and versatility of thrombolytic drugs to treat COVID-19. J Thromb Haemost. (2020) 18:154855. doi: 10.1111/jth.14872

18. Tang N, Bai H, Chen X, Gong J, Li D, Sun Z. Anticoagulant treatment is associated with decreased mortality in severe coronavirus disease 2019 patients with coagulopathy. J Thromb Haemost. (2020) 18:10949. doi: $10.1111 /$ jth.14817

19. Levi M, Thachil J, Iba T, Levy J. Coagulation abnormalities and thrombosis in patients with COVID-19. Lancet Haematol. (2020) 7:e43840. doi: 10.1016/S2352-3026(20)30145-9

20. Cui S, Chen S, Li X, Liu S, Wang F. Prevalence of venous thromboembolism in patients with severe novel coronavirus pneumonia. J Thromb Haemost. (2020) 18:1421-4. doi: 10.1111/jth.14830

21. Bangalore S, Sharma A, Slotwiner A, Yatskar L, Harari R, Shah B. ST-segment elevation in patients with covid-19 - a case series. N Engl J Med. (2020) 382:2478-80. doi: 10.1056/NEJMc2009020

22. Lodigiani C, Iapichino G, Carenzo L, Cecconi M, Ferrazzi P, Sebastian T, et al. Venous and arterial thromboembolic complications in COVID-19 patients admitted to an academic hospital in Milan, Italy. Thromb Res. (2020) 191:9-14. doi: 10.1016/j.thromres.2020.04.024

23. Fuster V, Sweeny JM. Aspirin: a historical and contemporary therapeutic overview. Circulation. (2011) 123.76878. doi: 10.1161/CIRCULATIONAHA.110.963843

24. Undas A, Brummel-Ziedins K, Mann K. Why does aspirin decrease the risk of venous thromboembolism? On old and novel antithrombotic effects of acetyl salicylic acid. J Thromb Haemost. (2014) 12:1776-87. doi: 10.1111/jth.12728

25. Myers D, Wrobleski S, Londy F, Fex B, Hawley A, Schaub R, et al. New and effective treatment of experimentally induced venous thrombosis with anti-inflammatory rPSGL-Ig. Thromb Haemost. (2002) 87:374-82. doi: 10.1055/s-0037-1613014

26. Ruggeri Z. Platelets in atherothrombosis. Nat Med. (2002) 8:122734. doi: $10.1038 / \mathrm{nm} 1102-1227$

27. Cadavid A. Aspirin: the mechanism of action revisited in the context of pregnancy complications. Front Immunol. (2017) 8:261. doi: 10.3389/fimmu.2017.0026

28. Zimmermann P, Curtis N. Antimicrobial effects of antipyretics. Antimicrob Agents Chemother. (2017) 61:e02268. doi: 10.1128/AAC.02268-16
29. Eikelboom J, Hirsh J, Spencer F, Baglin T, Weitz J. Antiplatelet drugs: antithrombotic therapy and prevention of thrombosis, 9th ed: American college of chest physicians evidence-based clinical practice guidelines. Chest. (2012) 141:e89S-119S. doi: 10.1378/chest.11-2293

30. Brighton T, Eikelboom J, Mann K, Mister R, Gallus A, Ockelford P, et al. Low-dose aspirin for preventing recurrent venous thromboembolism. $N$ Engl J Med. (2012) 367:1979-87. doi: 10.1056/NEJMoa1210384

31. Becattini C, Agnelli G, Schenone A, Eichinger S, Bucherini E, Silingardi M, et al. Aspirin for preventing the recurrence of venous thromboembolism. $N$ Engl J Med. (2012) 366:1959-67. doi: 10.1056/NEJMoa1114238

32. Simes J, Becattini C, Agnelli G, Eikelboom J, Kirby A, Mister $\mathrm{R}$, et al. Aspirin for the prevention of recurrent venous thromboembolism: the INSPIRE collaboration. Circulation. (2014) 130:1062-71. doi: 10.1161/CIRCULATIONAHA.114.008828

33. Huang C, Wang Y, Li X, Ren L, Zhao J, Hu Y, et al. Clinical features of patients infected with 2019 novel coronavirus in Wuhan, China. Lancet. (2020) 395:497-506. doi: 10.1016/S0140-6736(20)30183-5

34. Du Y, Tu L, Zhu P, Mu M, Wang R, Yang P, et al. Clinical features of 85 fatal cases of COVID19 from Wuhan: a retrospective observational study. Am J Respir Crit Care Med. (2020) 201:1372-9. doi: 10.1164/rccm.202003-0543OC

35. Yuki K, Fujiogi M, Koutsogiannaki S. COVID19 pathophysiology: a review. Clin Immunol. (2020) 215:108427. doi: 10.1016/j.clim.2020.108427

36. Panka B, de Grooth H-J, Spoelstra-de Man A, Looney M, Pieter-Roel Tuinman P-R. Prevention or treatment of ARDS with aspirin: a review of preclinical models and meta-analysis of clinical studies. Shock. (2017) 47:13-21. doi: 10.1097/SHK.0000000000000745

37. ClinicalTrials.gov. Available online at: www.clinicaltrials.gov (accessed October 6, 2020).

Conflict of Interest: The authors declare that the research was conducted in the absence of any commercial or financial relationships that could be construed as a potential conflict of interest.

Copyright (c) 2020 Diaz, Trachtenberg, Abraham, KosagiSharaf and DurantArchibold. This is an open-access article distributed under the terms of the Creative Commons Attribution License (CC BY). The use, distribution or reproduction in other forums is permitted, provided the original author(s) and the copyright owner(s) are credited and that the original publication in this journal is cited, in accordance with accepted academic practice. No use, distribution or reproduction is permitted which does not comply with these terms. 